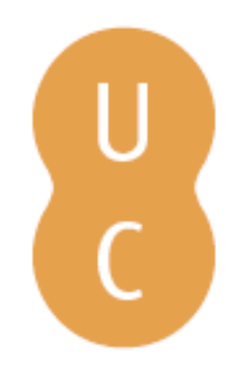

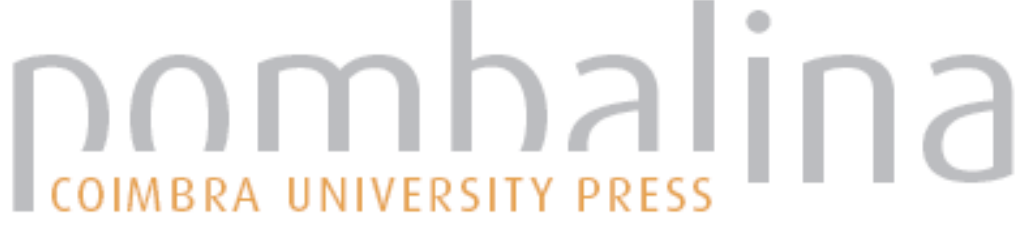

\section{Antropoceno, cidades e geografia}

Autor(es): $\quad$ Ferrão, João

Publicado por: Imprensa da Universidade de Coimbra

URL

persistente: URI:http://hdl.handle.net/10316.2/43485

DOI: $\quad$ DOI:https://doi.org/10.14195/978-989-26-1343-7_15

Accessed : $\quad$ 26-Apr-2023 09:25:16

A navegação consulta e descarregamento dos títulos inseridos nas Bibliotecas Digitais UC Digitalis, UC Pombalina e UC Impactum, pressupõem a aceitação plena e sem reservas dos Termos e Condições de Uso destas Bibliotecas Digitais, disponíveis em https://digitalis.uc.pt/pt-pt/termos.

Conforme exposto nos referidos Termos e Condições de Uso, o descarregamento de títulos de acesso restrito requer uma licença válida de autorização devendo o utilizador aceder ao(s) documento(s) a partir de um endereço de IP da instituição detentora da supramencionada licença.

Ao utilizador é apenas permitido o descarregamento para uso pessoal, pelo que o emprego do(s) título(s) descarregado(s) para outro fim, designadamente comercial, carece de autorização do respetivo autor ou editor da obra.

Na medida em que todas as obras da UC Digitalis se encontram protegidas pelo Código do Direito de Autor e Direitos Conexos e demais legislação aplicável, toda a cópia, parcial ou total, deste documento, nos casos em que é legalmente admitida, deverá conter ou fazer-se acompanhar por este aviso.

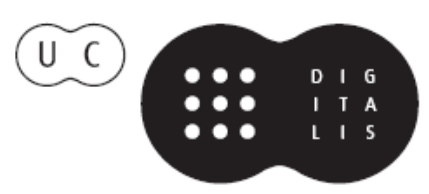




\section{FERNANDA CRAVIDÃO}

\section{IÚCIO CUNHA}

PAULA SANTANA

\section{NORBERTOSANTOS}

(ORG.)

\section{ESPAÇOS E TEMPOS EM GEOGRAFIA}

HOMENAGEM A ANTÓNIO GAMA

IMPRENISA DÁ UNIVERSIDADE DE COIMBRA COIMBRA UNIVERSITY PRESS

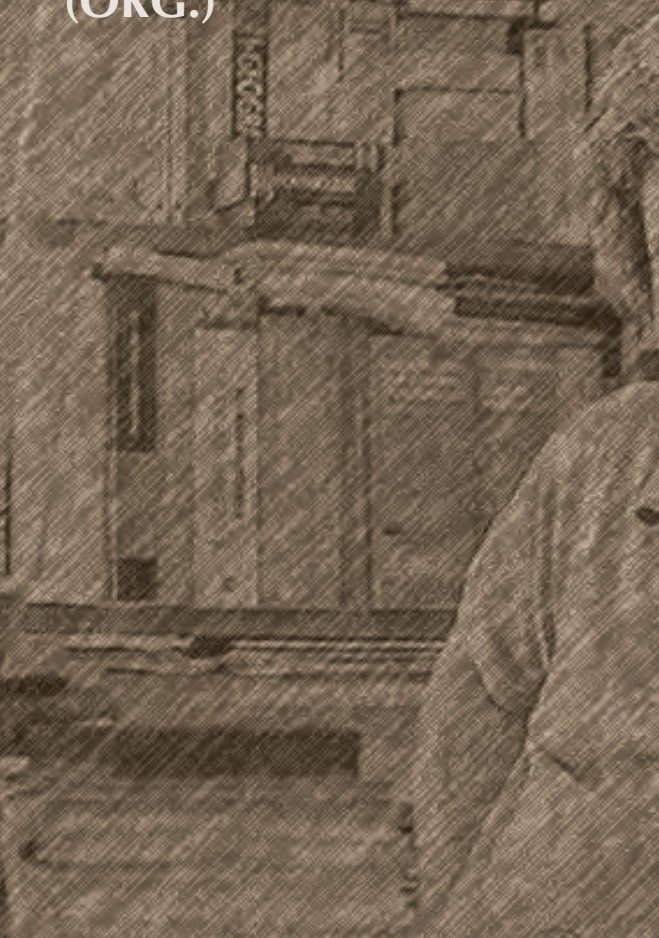




\title{
ANTROPOCENO, CIDADES E GEOGRAFIA
}

\author{
Joáo Ferráo/joao.ferrao@ics.ulisboa.pt \\ Instituto de Ciências Sociais \\ Universidade de Lisboa
}

"Who will speak for the Earth, and how, will it become one of the most crucial questions of the 21st century."

(Castree, 2015: 245)

\section{Nota prévia}

O António Gama cultivava o debate científico, tinha um enorme fascínio pelas cidades e era um apaixonado pela Geografia. O tema escolhido para este ensaio procura contemplar simultaneamente esses três aspetos. O Antropoceno é um conceito recente, com uma expansão fulgurante mas rodeado de controvérsia dentro e fora da academia, mobilizando, com igual intensidade, defensores, apoiantes críticos, céticos e detratores. O António não desperdiçaria esta oportunidade para exercitar o seu gosto pelo debate e para demonstrar a sua capacidade reflexiva em torno de um conceito provocador (Harrington, 2016). As cidades, por sua vez, constituem uma dimensão crítica da narrativa geo-histórica do Antropoceno (Taylor, O’Brien e O’Keefe, 2015b). Ganham, por isso, uma nova centralidade analítica e normativa neste contexto, o que permite aprofundar teses e perspetivas anteriores e, ao mesmo tempo, levantar questóes que apontam para horizontes inovadores de pesquisa e de ação. Por 
último, o Antropoceno e a sua relação estrutural com as cidades colocam o foco nas interaçóes entre sistemas sociais e sistemas biofísicos, entre humanos e não humanos, de tal modo que, conforme observa Castree (2015), tem suscitado o regresso à geografia de alguns geógrafos que entretanto se tinham afastado em direção a outros domínios. O triângulo Antropoceno - cidades - Geografia parece desenhado para ser debatido pelo António Gama. Discuti-lo-ia como poucos. E, suspeito, como apoiante crítico.

\section{Antropoceno: a rápida ascensáo de um conceito controverso}

Num texto anterior (Ferrão, 2016), apresentámos sucintamente o modo como o conceito de Antropoceno, lançado por Crutzen e Stoermer em 2000 numa simples newsletter do IGBP - International Geosphere - Biosphere Programme e apenas dois anos depois alvo de publicaçáo de um artigo na prestigiada revista Nature (Crutzen, 2002), abriu um ciclo de debate em torno da ideia de que teríamos entrado numa nova época geológica, marcada pela força da influência antropogénica na evolução dos sistemas biofísicos terrestres, nomeadamente no que se refere a alterações climáticas, à extinção de espécies naturais e a modificaçóes no uso do solo: o Antropoceno, ou seja, a época do homem. Em 3 de maio de 2016, uma consulta ao Google académico confirma que esta continua a ser a publicaçáo mais influente sobre o Antropoceno se levarmos em consideração o total de vezes que foi citada: 1635 .

Num texto posterior mais desenvolvido, redigido com outros autores (Steffen, Crutzen e McNeill, 2007), é justificada e caracterizada a emergência desta nova época geológica, apresentando-se uma periodização com início na revoluçáo industrial de finais do século Xviır ocorrida na Europa e identificando-se as opçôes com que nos confrontamos hoje face a esta nova realidade. De modo muito sumário, aquele texto desenvolve, em particular, as seguintes ideias ${ }^{1}$ :

\footnotetext{
1 Retoma-se, de forma parcial ou integral, a síntese apresentada nas primeiras duas páginas do texto Ferrão (2016).
} 
- Com o recurso intensivo da revolução industrial de finais do século XVIII/início do século XIX a combustíveis fósseis, os seres humanos tornaram-se uma força geofísica global que influencia de forma crescente a evolução do funcionamento do planeta Terra: os seres humanos, através das atividades que desenvolvem, constituem um agente transformador ativo da biosfera;

- A emergência do Antropoceno, desde essa altura até à atualidade, inclui duas fases: a etapa industrial (ca. 1800 - 1945), caracterizada pelo recurso sistemático ao uso de energias fósseis num contexto de modernização técnico-científica e de forte expansão urbano-industrial; e a etapa da Grande Aceleração (1945 - ca. 2015), marcada pelo aumento da exploraçáo de recursos finitos, da emissão de $\mathrm{CO} 2$, do aquecimento global, da degradação ambiental e da extinção de numerosas espécies animais e vegetais;

- O momento em que nos encontramos hoje confronta-se com vários cenários, desigualmente desejáveis, e cuja concretização dependerá das opçôes que prevalecerem globalmente: i) continuidade (business as usual), baseada na desvalorização sistemática da gravidade do problema e na crença de autorregulação da economia; ii) mitigaçáo, proporcionando o regresso ao período pré-Antropoceno através de soluçôes tecnocientíficas; iii) geoengenharia, assente na manipulação crescente dos processos de funcionamento do sistema terrestre acompanhada pelo reforço do papel regulador das instituiçóes internacionais; e, finalmente, iv) uma perspetiva alternativa, em que os seres humanos se assumem como cuidadores do sistema terrestre através do aumento da consciencialização dos impactos de origem humana na evolução do nosso planeta, da atribuiçấo de maior centralidade às questôes éticas associadas à produção e, ainda, de uma avaliação rigorosa dos efeitos colaterais não-esperados resultantes das perspetivas anteriores, sobretudo das soluçóes de geoengenharia 
Este texto de Steffen, Crutzen e McNeill corresponde ao começo de um debate académico aceso, que irá transbordar para as redes sociais, para a comunicação social e para alguns livros de divulgação mais ou menos sensacionalistas ou mesmo apocalíticos sobre o colapso da atual civilização, como consequência da grave crise ambiental induzida por forças antropogénicas fora do controlo humano.

Em 2009, é criado o Grupo de Trabalho sobre o Antropoceno (AWG Anthropocene Working-Group) por membros da Sociedade Geológica de Londres e outros especialistas no âmbito da Subcomissão da Estratigrafia do Quaternário, que integra a Comissão Internacional de Estratigrafia. O seu objetivo é alcançar o reconhecimento oficial do Antropoceno como época geológica, um desígnio até agora não atingido e que permanece sob contestação no seio da comunidade dos geólogos e de outros especialistas de áreas afins, embora se pense que o desejado reconhecimento possa ser obtido em breve. Mas o debate em torno do Antropoceno estava lançado. O ano de 2014 foi particularmente relevante para os defensores da nova época do 'homem': o Oxford English Dictionary inclui pela primeira vez uma entrada sobre 'Anthropocene'; é criado o periódico The Anthropocene Review, que publica, aliás, artigos pró e contra a 'narrativa do antropoceno'; realiza-se a primeira das reunióes anuais do AWG; ocorre o primeiro encontro internacional Anthropocene Curriculum \& Campus, por iniciativa da The Haus der Kulturen der Welt e do Max Planck Institut for the History of Science, com o objetivo de definir um currículo interdisciplinar sobre o Antropoceno que possa ser adotado por universidades de diferentes países. Em 2015 é editado um número temático da revista Geographical Research sobre "Geografias do Antropoceno". Nesse mesmo ano e em 2016, como assinala Castree (2016), diversos artigos sobre o Antropoceno foram publicados nas prestigiadas revistas Nature e Science, o que não deixa de refletir o grau de maturidade científica entretanto alcançado neste domínio temático.

Desde 2009, o total de pesquisas no Google da palavra Antropoceno (sobretudo em inglês, mas também em português/castelhano) teve um aumento significativo (Figura 1). É verdade que o Antropoceno permanece um conceito 'adolescente' (Castree, 2014c), de futuro incerto. Mas uma pesquisa realizada no Google Scholar em 14 de março de 2016 permitiu identificar cerca de 1.700 
publicaçóes com a palavra "Anthropocene" no título, estando 425 registadas na Web of Science e 550 na Scopus (Harrington, 2016:9).

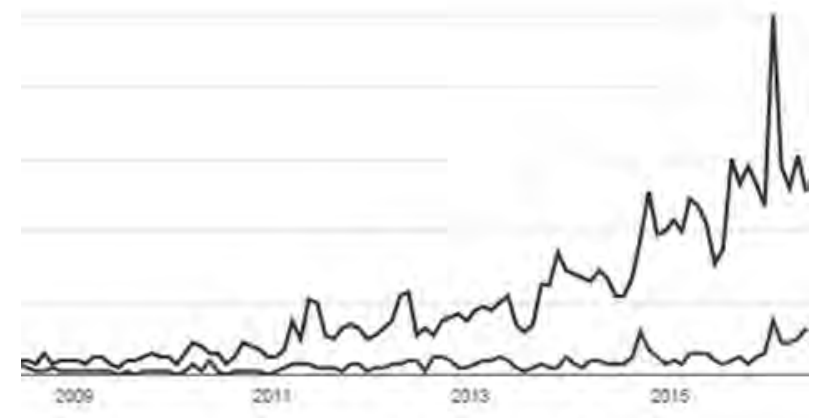

Figura 1

Evolução do total de pesquisas da palavra “antropoceno” no Google, 2009-2016

Fonte: https://www.google.com/trends/explore\#q=antropoceno $\% 2 \mathrm{C} \% 20$ anthropocene $\& \mathrm{cmpt}=\mathrm{q} \& \mathrm{tz}=\mathrm{Etc} \% 2 \mathrm{FGMT}-1$

Legenda: cinzento: 'anthropocene' (inglês); preto: 'antropoceno' (português/castelhano)

Nota: os valores do gráfico obedecem a uma escala de 0 a 100 , em que este último valor corresponde à ocorrência máxima mensal observada no período em análise, 2009-2016 (neste caso, janeiro de 2016); os restantes valores distribuem-se naquela escala em função da sua proporção em relação ao valor máximo atingido.

Entretanto, foram sendo criados diversos blogues especificamente dedicados ao Antropoceno, permitindo ampliar o debate, quer no seio da academia, quer no seu exterior.

Náo cabe, neste texto, aprofundar a discussão sobre o Antropoceno como época geológica, o seu início, os fatores que o explicam, os seus impactos globais em termos ambientais, sociais e económicos ou as suas implicaçôes éticas. A bibliografia disponível sobre estes temas, ainda que tenha uma incidência muito desigual nas várias áreas disciplinares, contaminou já as ciências sociais e as humanidades (ver, por exemplo, Palsson et. al., 2013) ${ }^{2}$ e mobiliza

2 Atente-se, no entanto, à deceção revelada por Harrington (2016: 9/10) quanto à ausência quase total de referências ao Antropoceno num dos principais encontros mundiais no domínio das 
aspetos e argumentos em número suficiente para confirmar que o conceito de Antropoceno proposto por Crutzen e Stoermer em 2000 foi capaz de suscitar um debate vivo mas ainda longe de estar estabilizado, merecendo, por isso, mais atenção e reflexão crítica (Castree, 2016).

O objetivo deste ensaio é, no entanto, mais modesto: relacionar a emergência do debate sobre o Antropoceno com a necessidade de adotar novas visóes acerca das cidades e a possibilidade de se abrirem novas oportunidades a uma Geografia que esteja disponível para redescobrir, reinventando-a, a sua tradição fundadora de visão integrada 'homem-meio'.

\section{Cidades e Antropoceno: uma relaçấo estrutural?}

Desde a revolução industrial iniciada em Inglaterra na segunda metade do século XVIII que as cidades não deixaram de crescer. Embora o conceito estatístico de cidade não seja consensual, estima-se que as áreas urbanas ocupem atualmente cerca de 3\% da superfície terrestre, concentrando um pouco mais de metade da população mundial. Tendo por base modelos de previsão probabilística, Seto et al. (2012) calculam que a população urbana em 2030 atingirá os 5 mil milhóes, correspondendo a um acréscimo de 1,2 milhóes de $\mathrm{km} 2 \mathrm{de}$ solo urbano, o que significa triplicar o espaço ocupado por cidades em 2000.

No contexto da relação cidades - Antropoceno, aquelas são crescentemente importantes não apenas pela população que concentram ou pela superfície que ocupam, mas também por outros motivos: por exemplo, consomem $76 \%$ dos recursos naturais do planeta e são responsáveis pela emissão de $60 \%$ dos gases com efeito de estufa (UN-HABITAT, 2015). Compreende-se, portanto, que exista uma relação forte e estrutural entre os processos de urbanização em

Relaçôes Internacionais: "The 2015 International Studies Association (ISA) Annual Conference, the largest annual event in the discipline, contained over 6000 presentations. Only one paper abstract explicitly mentioned the Anthropocene". 
curso à escala planetária e a emergência do Antropoceno (ver síntese efetuada em Biermann et al. (2015) na secção 2.3 sobre urbanização).

As cidades constituem os grandes palcos da transformação alargada das relaçōes entre os sistemas humanos/sociotécnicos e os sistemas biofísicos. A expansão das cidades canónicas, através de morfologias urbanas consolidadas, mas também das suas áreas envolventes, com subúrbios de diferentes densidades e com distintos graus de formalizaçáo, e ainda o aumento exponencial dos fluxos materiais interurbanos ao nível do planeta, induzem alterações profundas no funcionamento do sistema Terra pelo menos por quatro vias, as duas primeiras diretas e as restantes indiretas:

- Ocupação do solo: artificialização e impermeabilização da superfície terrestre, destruição e enterramento de linhas de água, terraplanagens, diminuição da biodiversidade, etc. (ver, por exemplo, Price et al., 2011, para o caso da Grã-Bretanha);

- Aquecimento urbano: criação de ilhas de calor urbano e alteração dos regimes dos ventos locais, com impactos, nomeadamente, ao nível da qualidade do ar (poluição atmosférica) e dos consumos de água e de energia $^{3}$;

- Aquecimento global: alteraçóes climáticas provocadas pela crescente emissão de gases com efeito de estufa, cujos impactos são hoje conhecidos, como o agravamento da ocorrência de fenómenos extremos, o aumento das temperaturas médias, a concentração dos períodos de chuva ou a subida do nível médio do mar, afetando, neste último caso, as cidades ribeirinhas ${ }^{4}$;

\footnotetext{
3 Ver, a este propósito, o número temático da revista Finisterra, Volume XLIX, número 98, organizado por Alcoforado (2014).

${ }^{4}$ A bibliografia sobre alterações climáticas e cidades é imensa. Ver, por todos, o capítulo da autoria de Revi et al. (2014), produzido pelo Grupo de Trabalho II do IPCC. É particularmente relevante, neste domínio, a proposta apresentada por diversas entidades (redes de cidades, autarcas, etc.) na 43a sessão do IPCC, realizada em Nairobi em abril de 2016, de elaboração de um relatório especial do IPCC sobre cidades e alterações climáticas.
} 
- Empobrecimento das relaçôes rural-urbano: degradação, nomeadamente por via dos efeitos das alteraçôes climáticas, das áreas rurais envolventes enquanto espaços de aprovisionamento das cidades (água, produtos alimentares, etc.) e de lazer das populaçôes urbanas (biodiversidade, qualidade paisagística, etc.), e crescente desconexão de ecossistemas transversais aos espaços rurais e urbanos (OECD, 2013; UN-HABITAT, 2015).

De entre os vários autores que têm vindo a escrever sobre cidades e Antropoceno, Taylor, O’Brien e O'Keefe destacam-se através da produção de três textos complementares onde procuram realçar a importância estrutural da relaçáo cidades - Antropoceno do ponto de vista analítico (papel das cidades na génese e no aprofundamento do Antropoceno) e da ação (novos estilos de vida e processos urbanos como superaçáo do Antropoceno). Para isso, apresentam o que designam por uma "nova narrativa geohistórica que coloca as cidades no coração das alteraçôes climáticas de origem antropogénica" (Taylor, O’Brien e O'Keefe, 2015b: 1).

Os autores limitam, portanto, o Antropoceno à componente antropogénica das alteraçóes climáticas, certamente a mais relevante mas não a única (recorde-se, como acima se referiu, o modo com a expansão urbana artificializa extensóes crescentes da superfície terrestre e destrói ecossistemas essenciais ao funcionamento da biosfera). Apesar dessa visão restrita, a tese que defendem é ambiciosa, assentando nas seguintes ideias-chave:

- O Antropoceno caracteriza-se por uma temporalidade multimilenar, tendo-se iniciado com a primeira revoluçáo urbana ocorrida há cerca de 8.000 anos (criação de cidades como Jericó ou Catalhörük); os autores rejeitam, pois, quer a narrativa da modernidade industrial defendida por Crutzen e muitos outros (o 'modelo dos dois séculos') quer a narrativa, proposta por Moore (2014), da modernidade do sistema-mundial iniciada com o movimento das 'descobertas' de navegadores europeus (o 'modelo dos 500 anos'). O Antropoceno terá, 
assim, uma temporalidade transmoderna, isto é, preexiste e acompanha a modernidade nas suas diversas etapas;

- À temporalidade multimilenar e transmoderna do Antropoceno associa-se uma espacialidade global, marcada pela expansão das cidades e pela transformação sistemática e generalizada do uso e da cobertura do solo decorrente da expansão da agricultura (via desflorestação, por exemplo), ou seja, uma espacialidade não inicialmente restrita, como nas narrativas da modernidade industrial ou da modernidade do sistema-mundo, à Europa ou, de forma mais genérica, aos espaços da sociedade dita ocidental;

- A importância das cidades decorre do efeito conjugado do seu papel como focos de desenvolvimento económico, de consumo, de inovação e de criatividade - isto é, de mudança - bem como das suas características cosmopolitas e de organização em rede, que favorecem fluxos de diversa natureza, os quais alargam os efeitos urbanos a escalas que ultrapassam em muito as áreas em que as cidades se localizam;

- Em função deste diagnóstico, os autores criticam o privilégio que tem vindo a ser atribuído às soluções centradas na mitigação da emissão de gases com efeito de estufa, considerados a principal fonte antropogénica das alteraçôes climáticas. Em alternativa, defendem a necessidade de “transcender a nossa herança moderna” (Taylor, O’Brien e O’Keefe, 2015b:9) através de uma $4 .^{\mathrm{a}}$ revolução industrial assente na adoção generalizada de novas formas de vida baseadas em consumos urbanos frugais no âmbito de redes verdes de cidades criativas. $\mathrm{O}$ foco da mudança, na ótica destes autores, não deve ser, portanto, a concretização, cidade a cidade, de açóes de mitigação e de adaptação baseadas em soluçóes tecnológicas inovadoras, mas sim a opção global por novos estilos de vida coletivos sustentáveis. A dimensão urbana crítica para a mudança reside, assim, no consumo e nos modos de viver (Taylor, O’Brien e O’Keefe, 2015a);

- A generalização de estilos de vida coletivos sustentáveis exige a superação dos modelos económicos baseados no crescimento contínuo, ou 
seja, do 'capitalismo' como acumulação permanente (Taylor, O’Brien e O'Keefe, 2015c).

Em síntese, esta narrativa multimilenar, transmoderna e global de Antropoceno implica a substituição da perspetiva moderna assente no que designamos, tentando sintetizar a perspetiva destes autores, pela equação "cidades como lugares + economia como crescimento contínuo + tecnologias como solução + políticas estatais e negociações intergovernamentais como resposta política" pela equação "cidades como processos + desenvolvimento não baseado no crescimento económico + novos modos de vida e de consumo sustentáveis + processos de decisão ascendentes (bottom-up)", isto é, pelo que Taylor, O’Brien e O'Keefe classificam como uma visão utópica de redes verdes de cidades criativas e promotoras da inovação societal.

As propostas destes autores são ambiciosas, arrojadas e, para muitos, irrealistas. Mas a verdade é que outros textos, incluindo publicaçôes de entidades internacionais ou supranacionais, colocam igualmente o foco na necessidade urgente de reconciliar a cidade com a natureza, o desenvolvimento urbano com a biosfera, nomeadamente através do entendimento das cidades como sistemas socioecológicos e não, como sucede na visão moderna, como sistemas sociotécnicos, isto é, em que os avanços tecnológicos foram permitindo construir as cidades 'contra' a natureza em vez de se moldarem a ela e a valorizarem. A 'renaturalização' das cidades contemporâneas ou, de forma mais pragmática, o desenvolvimento de soluçóes baseadas na natureza (nature-based solutions) e de infraestruturas verdes 5 , são, assim, enaltecidos quer em textos académicos (ver, por exemplo, Scott e Lennon, 2016, e o dossiê temático por eles organizado no n. ${ }^{\circ}$ 17(2) da revista Planning Theory \& Practice), quer em estudos publicados pela Comissão Europeia (EC, 2015).

O entendimento da cidade como sistema socioecológico leva a colocar a natureza no centro dos processos de metabolismo urbano (Lennon e Scott, 2016) e a defender a necessidade de gerir os espaços urbanos a partir de uma

${ }^{5}$ Sobre o conceito de infraestrutura verde, ver Comissăo Europeia (2013). 
visão de coexistência e de coevolução dos diferentes sistemas sociais e ecológicos (Haase, 2016). E é justamente aqui que nos encontramos com a Geografia. Esta preocupaçáo, ainda que formulada numa linguagem distinta, faz parte da sua tradiçâo fundadora como comunidade científica autónoma. A relação Antropoceno - cidades - Geografia pode, assim, criar novas oportunidades a uma disciplina que se institucionalizou no final do século XIX tendo como principal objeto de estudo as relaçóes 'homem - meio' em diferentes regiôes da superfície terrestre.

\section{O Antropoceno visto a partir das cidades: o regresso da Geografia integrada?}

Cook, Rickards e Rutherfurd (2015) recorrem à metáfora do 'ponto de encontro' (meeting-point) para salientar que o debate em torno do Antropoceno, das suas origens e dos seus efeitos, pode criar uma oportunidade para retomar uma geografia unitária, pelo menos em alguns domínios subdisciplinares, que, ao colocar o foco de atenção nas relaçôes humanos - natureza, supere a divisão ontológica moderna que levou à sua separação.

A Geografia institucionalizou-se como disciplina autónoma, no final do século XIx, em torno de dois grandes objetivos: o estudo da distribuição de diferentes fenómenos na superfície terrestre (clima, espécies animais e vegetais, povoamento, produções agrícolas, atividades económicas, culturas, etc.) e o estudo das relaçóes 'entre o homem e o meio'. Do ponto de vista analítico, é este segundo objetivo que vai marcar a então nova disciplina, conferindo-lhe unidade interna e, ao mesmo tempo, diferenciando-a das restantes. Quer na sua versão inicial de determinismo geográfico, em que as características geográficas de uma dada área eram vistas como fatores que determinavam os atributos físicos, culturais e económicos de quem nelas habitava (nas planícies predomina o monoteísmo, nas ilhas os habitantes são pescadores, nas regióes calcárias as mulheres são mais vulneráveis, etc.), quer na perspetiva posterior do possibilismo, em que se reconhecia que as comunidades humanas podiam 
responder de forma diferenciada ao mesmo tipo de características geográficas em função dos seus modos de vida e do tipo de civilização prevalecente, o estudo da relação 'homem-meio' permaneceu até meados do século passado como o objeto de estudo por excelência da Geografia.

Esta visão ecológica fundacional da disciplina apenas virá a ser colocada em causa, e mesmo rejeitada, nos anos 60 do século xx. A visão moderna neopositivista da autodesignada Nova Geografia substitui entáo as perspetivas ecológicas clássicas, levando a que a geografia física e a geografia humana se afastem cada vez mais uma da outra e, ao mesmo tempo, se aproximem de outros domínios científicos: as geociências, no primeiro caso; a economia e as ciências sociais, no segundo. A quebra da velha unidade da Geografia, lamentada pelos geógrafos clássicos mas menosprezada ou mesmo celebrada pelos geógrafos 'modernos', vai-se consolidando como uma inevitabilidade natural. Afinal, a modernidade significava, justamente, a libertaçáo das sociedades em relação à natureza, domesticada nuns casos, ou destruída noutros, em nome do progresso e do crescimento económico. O estudo das relaçóes 'homem-meio' parecia deixar de ter sentido.

É verdade que, poucos anos mais tarde, os excessos da modernidade vão levar a que se atribua, na Geografia como em outras áreas científicas, particular atençáo aos riscos e impactos ambientais decorrentes dos processos de urbanização e de produção e consumo intensivos em recursos finitos. Mas mesmo esta preocupação não foi suficientemente forte para induzir uma nova relação entre especialistas de geografia física e de geografia humana centrada no estudo sistemático das inter-relaçôes entre sistemas sociais e sistemas biofísicos.

Será que o tema Antropoceno poderá romper essa tendência de afastamento recíproco entre os dois grandes subdomínios da Geografia? Ou, nas palavras de Cook, Rickards e Rutherfurd (2015), constituirá este conceito um ponto de encontro entre eles, ou, pelo menos, entre algumas das especialidades existentes no seio de cada um deles? Que contributo poderá o tema Antropoceno dar à Geografia e, ao mesmo tempo e simetricamente, que valor poderáo os geógrafos acrescentar aos debates sobre este novo conceito? Contribuiráo os geógrafos, mantendo as suas especialidades, para investigaçóes e debates crescentemente 
temáticos e interdisciplinares? Ou serão, antes, reforçadas as visões integradas no interior da comunidade dos geógrafos?

É, naturalmente, demasiado cedo para encontrar respostas definitivas em relação a estas várias questões. Autores como Castree (2014a, 2014b, 2014c, 2015) têm tentado vislumbrar tendências nesse sentido, através de uma análise cuidada da produção científica recente dos geógrafos e mesmo das suas trajetórias pessoais. Deste último ponto de vista, é particularmente interessante o exemplo de Mike Hulme, um geógrafo que se tornou um especialista em clima e que retornou agora à Geografia em função dos desafios colocados pelo tema Antropoceno (Castree, 2015: 248).

A relação Antropoceno-Geografia é sobretudo evidente nas cidades, afinal os territórios na linha da frente da concentração de causadores e de vítimas deste reforço crescente e incontrolado da ação humana como fator de transformação do planeta Terra. A tríade Antropoceno - cidades - Geografia é demasiado relevante para ser ignorada. Mas mesmo 'pontos de encontro' bem localizados nem sempre conseguem induzir as necessárias interaçóes.

\section{Comentário final}

Ao descrever o modo como a morfologia e as funçóes das cidades se ajustam aos sitios onde se implantam e expandem ou ao salientar as particularidades do urbanismo de colina recorrente nas cidades portuguesas, Orlando Ribeiro (Ribeiro, 1969), no primeiro caso, e Manuel Costa Lobo (Costa Lobo e Júnior, 2012), no segundo, caracterizavam realidades pré-modernas e, por isso, consideradas por muitos como inevitavelmente condenadas porque desajustadas às necessidades quotidianas das sociedades modernas.

Do ponto de vista da conceção moderna de sociedade e de economia, essas críticas são pertinentes. Mas a controvérsia em torno do Antropoceno, como sucede com outros debates, relembra-nos os limites da modernidade e apela-nos para que adotemos perspetivas e soluçóes que a transcendam nas suas várias metamorfoses, do 'velho' capitalismo urbano-industrial à atual fase de 
capitalismo global urbano-financeiro. A visão socioecológica de cidade não é um regresso a perspetivas organicistas do passado nem se baseia na ideia de equilíbrio harmonioso entre 'o homem e o meio'. Tensóes e contradiçóes, dissensos e compromissos, instabilidade e incerteza, fazem parte, mais do que nunca, das sociedades complexas contemporâneas. Mas a visão socioecológica de cidade resgata valores e princípios analíticos e de ação importantes que o projeto moderno de sociedade orgulhosamente rejeitou, como o respeito pela natureza ou a gestão da coevolução dos sistemas sociais e biofísicos.

Poderão um conceito contestado, como o Antropoceno, uma disciplina socialmente pouco valorizada, como a Geografia, e uma realidade crescentemente complexa, como as cidades, reforçarem-se reciprocamente de modo a melhor garantir a sustentabilidade do planeta Terra como casa comum? António Gama teria, certamente, algo a dizer sobre o assunto. A partir de uma posição, estou convencido, que oscilaria entre o otimismo crítico e o ceticismo cooperante.

\section{Referências}

Alcoforado, M. J. (2014). Issue on Applied Human Bioclimatology in memory of Henrique Andrade, Finisterra, Volume XLIX (98), pp. 3-14.

Biermann, F. et al. (2015). Down to earth: Contextualizing the Anthropocene, Global Environmental Change.

http://dx.doi.org/10.1016/j.gloenvcha.2015.11.004 (acesso: 03.05.2016)

Castree, N. (2014a). The Anthropocene and geography I: The back story, Geography Compass, 8(7), pp. 436-449.

Castree, N. (2014b). Geography and the Anthropocene II: Current contributions, Geography Compass: 8(7), pp. 450-463.

Castree, N. (2014c). The Anthropocene and geography III: Future directions, Geography Compass, 8(7), pp. 464-476.

Castree, N. (2015). Geographers and the discourse of an earth transformed: influencing the intellectual weather or changing the intellectual climate?, Geographical Research, 53(3), pp. 244-254 .

Castree, N. (2016). Anthropocene Science: There may be trouble ahead, EnviroSociety, 7 April. www.envirosociety.org/2016/04/anthropocene-science-there-may-be-trouble-ahead (acesso: 03.05.2016)

Comissão Europeia (2013). Infraestrutura Verde — Valorizar o Capital Natural da Europa, COM(2013) 249 final, 6.5.2013. 
Cook, B. R.; Rickards, L. A. \& Rutherfurd, I. (2015). Geographies of the Anthropocene, Geographical Research, 53(3), pp. 231-243.

Costa Lobo, M. L. da \& Júnior, J. G. S. (org.) (2012). Urbanismo de Colina: uma Tradição Luso-brasileira, SciELO-Editora Mackenzie.

Crutzen, P. J. (2002). Geology of mankind, Nature, 415.6867, p. 23.

Crutzen, P. J. \& Stoermer, E. F. (2000). The Anthropocene, Global Change Newsletter, 41, pp. 17-18 .

EC (2015). Towards an EU Research and Innovation Policy Agenda for Nature-Based Solutions \& Re-Naturing Cities. Final Report of the Horizon 2020 Expert Group on 'Nature-Based Solutions and Re-Naturing Cities', Directorate-General for Research and Innovation, Luxembourg: Publications Office of the European Union, 2015.

http://www.kowi.de/Portaldata/2/Resources/horizon2020/coop/Expertenbericht_zu_Nature_based_ Solutions.pdf (acesso: 02.05.2016)

Ferrăo, J. (2016). As geografias rurais do Antropoceno: ainda uma terra incognitae? In Neves, António Oliveira das (Org.), Agricultura, Florestas e Desenvolvimento Rural, Ediçáo IESE, Lisboa.

Haase, D. (2016). Reflections on urban landscapes, ecosystems services and nature-based solutions in cities, Planning Theory \& Practice, 17(2), pp. 276-280.

Harrington, C. (2016). The ends of the world: International relations and the Anthropocene. Millennium: Journal of International Studies, pp. 1-21.

http://intl-mil.sagepub.com/content/early/2016/04/07/0305829816638745.full.pdf+html

(acesso: 26.04.2016)

Lennon, M. \& Scott, M. (2016). Re-naturing the city, Planning Theory \& Practice, 17(2), pp. 270-276 .

Moore, J. W. (2014). The Capitalocene part I: On the nature and origins of our ecological crisis.

http://www.jasonwmoore.com/uploads/The_Capitalocene__Part_I__June_2014.pdf (acesso: 01.03.2016)

OECD (2013). Rural-Urban Partnerships: An Integrated Approach to Economic Development, OECD Rural Policy Reviews, OECD Publishing, Paris.

Palsson, G. et al. (2013). Reconceptualizing the 'Anthropos' in the Anthropocene: Integrating the social sciences and humanities in global environmental change research, Environmental Science \& Policy, 28, pp. 3-13.

Price, S. J.; Ford, J. R.; Cooper, A. H. \& Neal, C. (2011). Humans as major geological and geomorphological agents in the Anthropocene: the significance of artificial ground in Great Britain, Philosophical Transactions of the Royal Society of London A: Mathematical, Physical and Engineering Sciences, 369(1938), pp. 1056-1084.

Revi, A.; Satterthwaite, D. E.; Aragón-Durand, F.; Corfee-Morlot, J.; Kiunsi, R. B. R.; Pelling, M.; Roberts, D. C. \& Solecki, W. (2014). Urban Areas, In Climate Change 2014: Impacts, Adaptation, and Vulnerability. Part A: Global and Sectoral Aspects. Contribution of Working Group II to the Fifth Assessment Report of the Intergovernmental Panel on Climate Change. Cambridge University Press, Cambridge, United Kingdom and New York, NY, USA, pp. 535-612. http://ipcc-wg2.gov/AR5/images/uploads/WGIIAR5-Chap8_FINAL.pdf (acesso: $03.05 .2016)$ 
Ribeiro, O. (1969). Proémio metodológico ao estudo das pequenas cidades portuguesas, Finisterra, 4(7), pp. 64-75.

Scott, M. \& Lennon, M. (2016). Nature-based solutions for the contemporary city, Planning Theory \& Practice, 17(2), pp. 267-270.

Seto, K. C.; Güneralp, B. \& Hutyra, L. R. (2012). Global forecasts of urban expansion to 2030 and direct impacts on biodiversity and carbon pools, Proceedings of the National Academy of Sciences, 109(40), pp. 16083-16088.

Steffen, W.; Crutzen, P. J. \& McNeill, J. R. (2007). The Anthropocene: are humans now overwhelming the great forces of nature? AMBIO: A Journal of the Human Environment, 36 (8), pp. 614-621.

Taylor, P. J.; O’Brien, G. \& O'Keefe, P. (2015a). Human control of climate: Introducing cities, GaWC Research Bulletin, 446 (edited and posted on the web on 11th December 2015). http:// www.lboro.ac.uk/gawc/rb/rb446.html (acesso: 01.03.2016)

Taylor, P. J.; O'Brien, G. \& O'Keefe, P. (2015b). A Trans-modern understanding of anthropogenic climate change through cities, GaWC Research Bulletin, 447 (edited and posted on the web on 11th December 2015). http://www.lboro.ac.uk/gawc/rb/rb447.html (acesso: 01.03.2016)

Taylor, P. J.; O'Brien, G. \& O'Keefe, P. (2015c). Ten antitheses on cities and states: Challenging the mindscape of chronology and chorography in anthropogenic climate change, GaWC Research Bulletin, 448 (edited and posted on the web on 11th December 2015). http://www. lboro.ac.uk/gawc/rb/rb448.html (acesso: 01.03.2016)

UN-HABITAT (2015). Habitat III Issue Papers 10 - Urban-Rural Linkages, New York, 31 May 2015 (not edited version 2.0). http://unhabitat.org/wp-content/uploads/2015/04/Habitat-III-Issue-Paper-10_Urban-Rural-Linkages-2.0.pdf (acesso: 03.05.2016) 